[DOI: 10.24214/jecet.A.9.1.13037.]

Jaurnal of Enviranmental Science, Camputer Science and Engineering \& Technology

An International Peer Review E-3 Journal of Sciences and Technology

Available online at www.jecet.org

Section A: Environmental Science

Research Article

\title{
Performance Simulation and Optimization of Single Gas Chamber Hydro-pneumatic Spring in Low Temperature Environment
}

\author{
Yaqian Zhou ${ }^{\text {* }}$, Hui $\mathrm{Li}^{1}$, Yufeng Liu' ${ }^{2}$ and Yi Wang ${ }^{1}$ \\ School of Transportation and Vehicle Engineering, Shandong University of \\ Technology, Zibo 255049, China ${ }^{1 *}$; \\ Taiyuan Heavy Machinery Group Yuci Hydraulic Industry (Jinan) Co., LTD, Jinan \\ 250000, China $^{2}$
}

Received: 13 December 2019; Revised: 30 December 2019; Accepted: 08 January 2020

\begin{abstract}
Physical models of hydro-pneumatic spring with single chamber are established to solve the problem of the failure under low temperature and the pressure of the damping hole is simulated by AME Sim software. The effects of the temperature change on the differential pressure of the damping hole at both ends are comparative analyzed by simulation and test, and the optimization measures are put forward. The results could provide reference that when the vehicle is driven under low temperature and severe conditions, the absolute viscosity increases and the pressure difference at both ends of the damping hole of the recovery stroke increases; Increasing appropriately the diameter of the damping hole of the hydro-pneumatic spring will reduce the damping force and keep the hydro-pneumatic spring within the optimal damping range; The electromagnetic proportional directional valve is added in the hydro-pneumatic spring to control the diameter of the damping hole to ensure the smooth running of the vehicle.
\end{abstract}

Keywords: hydro-pneumatic spring, damping hole, low temperature, absolute viscosity, AMESim. 


\section{INTRODUCTION}

Hydro-pneumatic spring is mainly used in heavy vehicle suspension, which improves the design of traditional vehicles suspension's shock absorber and spring. The combination of check valve and damping hole replaces the damping characteristics of shock absorber.

The traditional spring is replaced by the accumulator filling with nitrogen gas. Its good nonlinear stiffness and nonlinear damping characteristic to improve vehicle ride comfort is of great importance ${ }^{1}$. However, under the condition of low temperature, the absolute viscosity of hydro-pneumatic spring (It's also called dynamic viscosity and it is the characterization of liquid damping characteristic quantities.) can cause rebound stroke damping force increases.

As a result, the pressure hydraulic cylinder chamber with piston-rod is too big, which can put forward higher requirement of the strength of the oil and gas spring and add difficulty to the design of hydropneumatic spring ${ }^{2-4}$. Therefore, research on hydro-pneumatic spring damping force is of great significance to improve its performance under the condition of low temperature.

Changcheng Zhou ${ }^{5}$, investigated in oil temperature, such as the effects of parameters of hydropneumatic spring throttle valve, puts forward the analytical design method, but did not calculate the damping under different temperature differential pressure at the ends of the hole which can well reflect the size of hydro-pneumatic spring damping force. The hydro-pneumatic spring physical model is established by Ying Fang ${ }^{7-8}$.

This paper optimizes the structure design of single gas chamber hydro-pneumatic spring, establishes the simulation experiment of single gas chamber hydro-pneumatic spring under low temperature condition, and puts forward the specific solution of vehicle driving under low temperature condition, which has certain guiding significance for the development and application of hydro-pneumatic spring

\section{WORKING MECHANISM OF HYDRO-PNRUMATIC SPRING}

When the hydro-pneumatic spring is in the compression stroke ${ }^{1}$, the piston rod moves downward, and the oil without the rod chamber (chamber III) moves in two directions under compression. Part of the oil enters the accumulator, reducing the volume of the gas chamber and increasing the nitrogen pressure. Another part of the oil enters the internal rod chamber (chamber III) and flows into the external rod chamber (chamber II) through the check valve and damping hole.

In this process, the internal rod chamber (chamber III) and the external rod chamber (chamber II) are connected by the check valve and damping hole. The velocity of oil flowing through the check valve and damping hole is low and the oil damping force is small. Therefore, it is mainly produced by the gas compressed within the accumulator elastic function to suppress the downward movement of the piston rod.

When the hydro-pneumatic spring is in the extending stroke, the piston rod moves upward, increasing the volume of the gas chamber and reducing the pressure. The oil of the external rod chamber (chamber II) and the accumulator IV flow into rodless cavity (chamber I). At the same time, check valve is closed. The oil of the external rod chamber (chamber II) only flows into damping hole. As a result, the damping force is bigger, which can be used in vibration attenuation. 


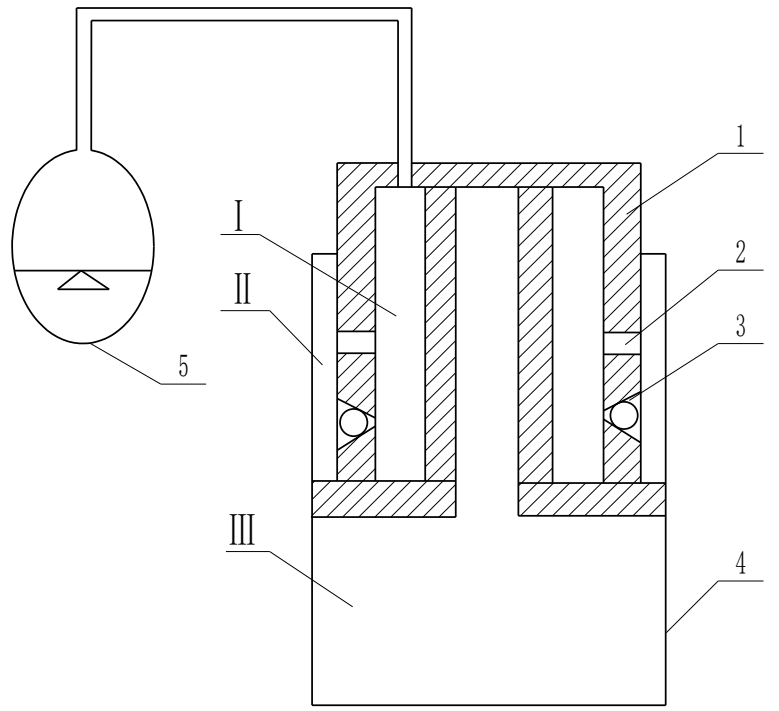

Fig.1: The structure principle plot of single gas chamber hydro-pneumatic spring

1. Piston rod and piston assembly 2. Check valve 3. Damping hole 4. Cylinder barrel 5. Accumulator

\section{EFFECT OF TEMPERATURE ON ABSOLUTE VISCOSITY OF HYDRO-PNEUMATIC SPRING}

When a liquid flows (or tends to flow) under the action of external forces, an internal friction force is produced, which prevents the relative motion of the molecules from occurring due to the cohesion of the liquid molecules. The property of this internal friction force becomes the viscosity of the liquid. The presence of viscosity results in pressure loss and internal damping ${ }^{5}$. The relationship between absolute viscosity and temperature of oil-gas spring is shown as follows ${ }^{6}$.

$$
\mathrm{R}=0.0089 * e^{-0.017 *(T-20)}
$$

Where, $\mathrm{T}$ is temperature, $\mathrm{R}$ is the absolute viscosity of hydro-pneumatic spring. The curve diagram of absolute viscosity with temperature is shown in Fig. 2.

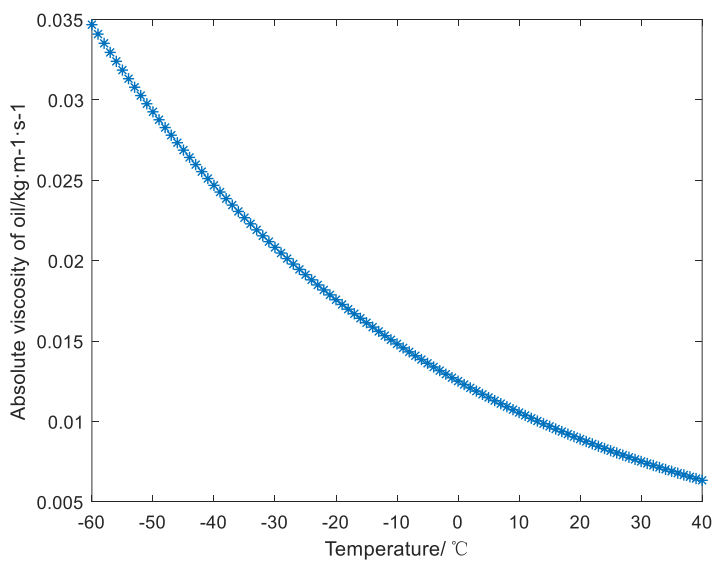

Fig.2: The relationship of absolute viscosity and temperature 
As can be seen from the figure, as the temperature decreases, the absolute viscosity increases, and the rate of increase is getting faster and faster.

\section{MODELING AND SIMULATION OF HYDRO-PNEUMATIC SPRING}

In order to facilitate the analysis, the damping hole in the hydro-pneumatic spring is simplified into a fixed throttle hole. The hydro-pneumatic spring dynamic model is built according to the hydropneumatic spring schematic diagram.

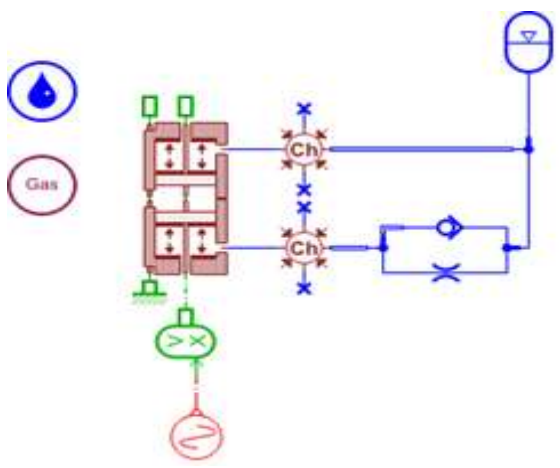

Fig.3: AME Sim simulation model of single-chamber hydro-pneumatic spring

As shown in Fig.3, a sinusoidal signal is input to the hydro-pneumatic spring to simulate the real circuit spectrum. The displacement signal is transferred to the oil cylinder through the signal converter. When the input signal is positive, the piston pushes the oil downward and enters the compression stroke. Parts of the oil without rod chamber flows into the rod chamber through the check valve and the damping hole. The oil flow rate is relatively gentle and the damping force is small. At this point, the oil in the accumulator is pressurized, acting as a spring rigidity to mitigate the signal shock from the road.

When the sinusoidal signal is negative, the piston moves up, entering the extending stroke. Antrum oil has been compressed, and the check valve closed. Therefore, the oil can only be accessed by damping hole like entering a narrow aperture. The velocity is large, and the damping force is big. At the moment, the energy of system is used to eliminate of damping force, which weakens the vibration.

Table 1: The basic simulation parameters of hydro-pneumatic spring

\begin{tabular}{c|c|c}
\hline Parameter & Numerical & Unit \\
\hline piston diameter & 60 & $\mathrm{~mm}$ \\
\hline rod diameter & 40 & $\mathrm{~mm}$ \\
\hline gas precharge pressure & 3 & $\mathrm{MPa}$ \\
\hline polytropic index & 1.4 & $\mathrm{~Hz}$ \\
\hline sine wave frequency & 0.5 & $\mathrm{~mm}$ \\
\hline sine wave amplitude & 50 & $\mathrm{~mm}$ \\
\hline diameter & 5 & - \\
\hline
\end{tabular}


By changing the absolute viscosity of the hydro-pneumatic spring, the differential pressure curve of both ends of the damping hole is obtained.

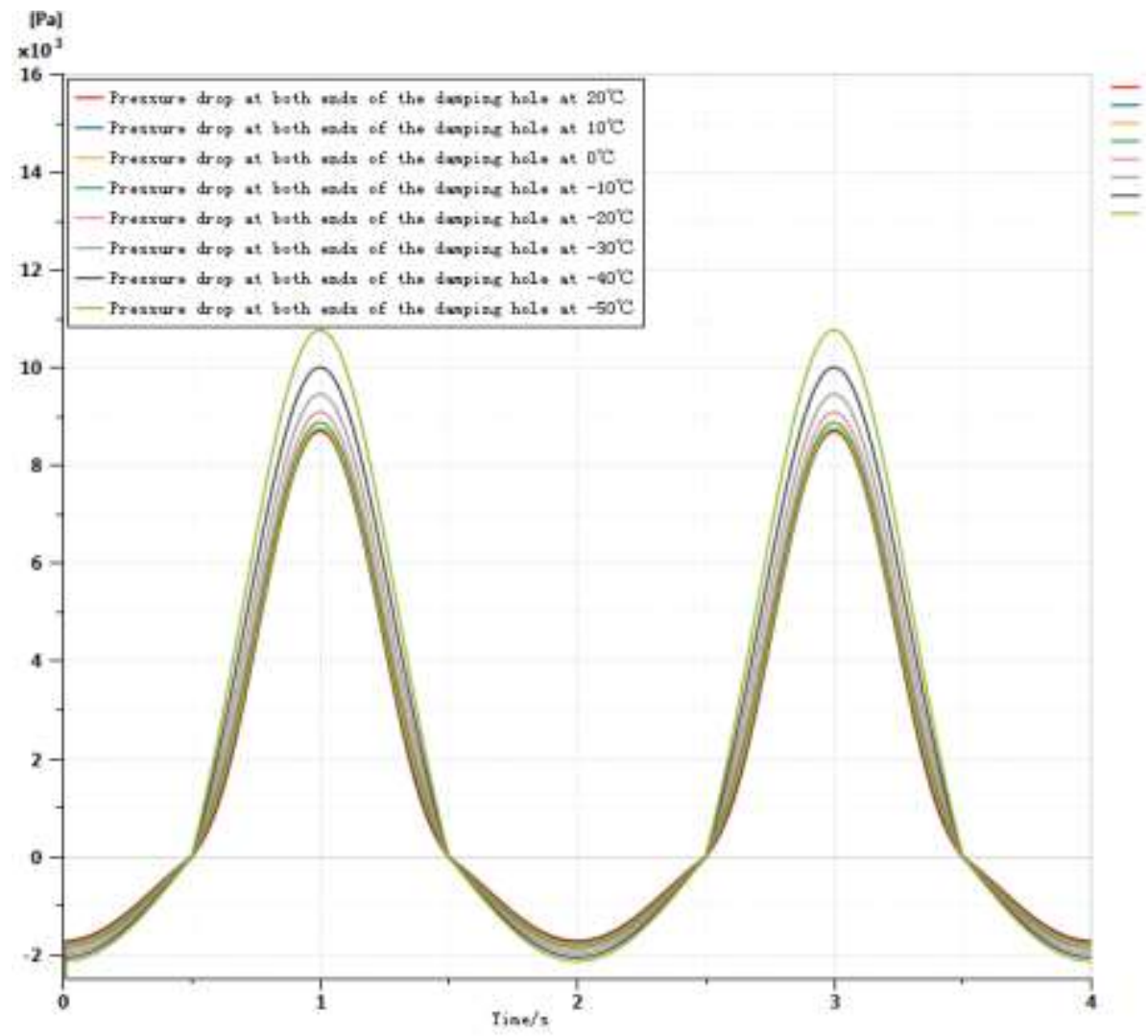

Fig.4: Pressure drop at both ends of the damping hole at different temperatures

As can be seen from Fig.4, the absolute value of the minimum pressure difference between the two ends of the damping hole is not significantly different at different temperatures, and the absolute value of the minimum pressure difference is far less than the maximum value of the pressure difference. This is because the oil flows to the check valve and the damping hole at the same time during the compression stroke. As a result, the damping force is small and the pressure difference between the two ends of the damping hole is small. The oil can only flow through the damping hole, resulting in a larger damping force and a larger pressure difference between the two ends of the damping hole.

When the temperature reaches $-50^{\circ} \mathrm{C}$, the maximum pressure difference at both ends of the damping hole reaches 10772.09Pa, while the normal temperature damping hole pressure difference is 8703.722 $\mathrm{Pa}$, which is higher than the normal temperature damping hole pressure difference at $20^{\circ} \mathrm{C}$. It can be seen that the damping force of the hydro-pneumatic spring has far exceeded the normal temperature damping value, which will cause the internal structure of the oil-gas spring to wear out or even fail. Similarly, when the temperature is $-40^{\circ} \mathrm{C},-30^{\circ} \mathrm{C},-20^{\circ} \mathrm{C}$ and $-10^{\circ} \mathrm{C}$ respectively, the damping force is larger than the damping value at room temperature. In order to give better play to the damping performance of the hydro-pneumatic spring, the damping hole diameter of the hydro-pneumatic spring needs to be optimized. 


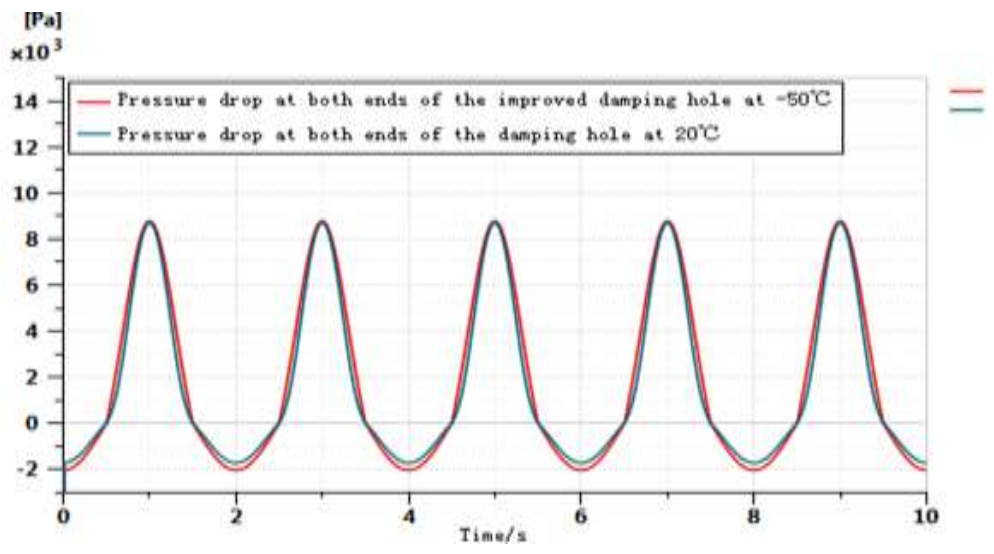

Fig.5: The pressure difference between the two ends of the damping hole

As shown in Fig.5, when the temperature is $-50^{\circ} \mathrm{C}$, the diameter of the damping hole is designed to be 5.3, and the maximum pressure difference at both ends of the damping hole and the time-varying curve of the pressure difference at room temperature basically coincide, indicating that appropriate increase in the diameter of the damping hole has a good regulating effect on the excessive damping force caused by low temperature environment.

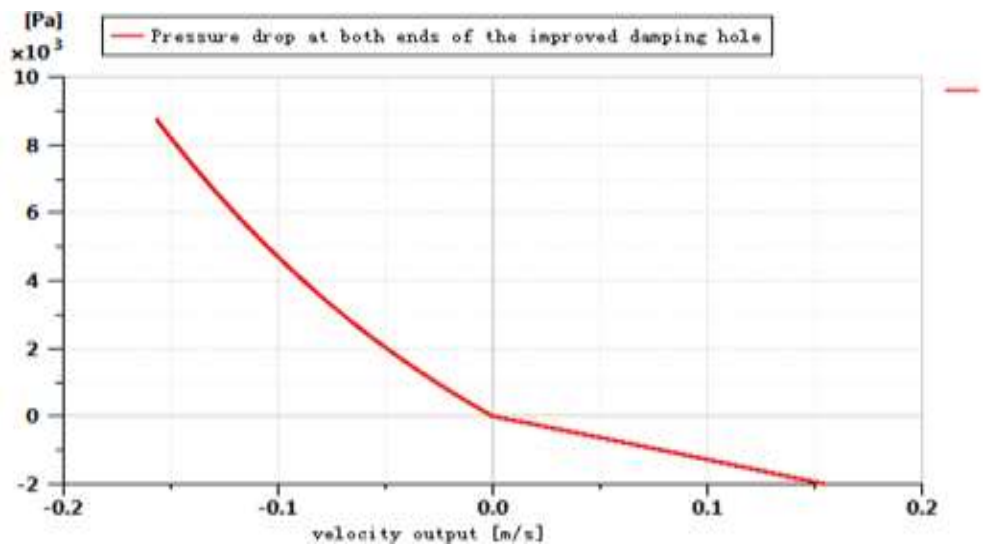

Fig.6: The relationship between pressure drop at both ends of the improved damping hole and the output velocity at $50^{\circ} \mathrm{C}$

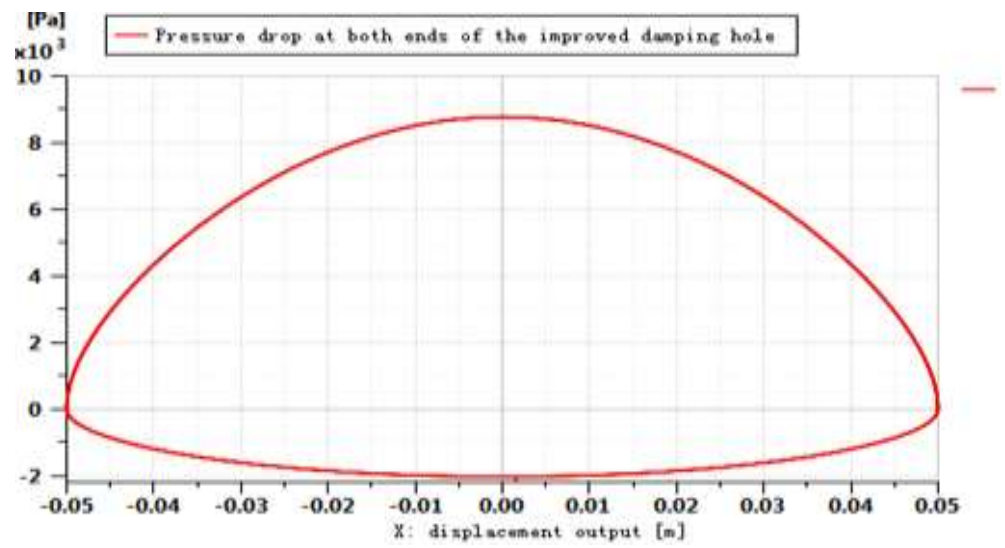

Fig.7: The relationship between pressure drop at both ends of the improved damping hole and displacement output 
Fig.6 shows that the pressure difference at both ends of the improved damping hole changes with the input velocity when the temperature is $-50^{\circ} \mathrm{C}$, reflecting the good nonlinear characteristics of the hydro-pneumatic spring. Fig.7 shows that the pressure difference at both ends of the improved damping hole changes with the input displacement when the temperature is $-50^{\circ} \mathrm{C}$. The pressure difference at both ends of the damping hole of the stretching stroke is far greater than that of the compression stroke, which conforms to the damping characteristics of the hydro-pneumatic spring. It indicates that the improved oil and gas spring can work normally.

\section{OPTIMIZATION OF HYDRO-PNEUMATIC SPRING STRUCTURE}

By changing the diameter of the damping hole, AMESim simulation is used to obtain the pressure difference curve at both ends of the damping hole at different temperatures, so that the pressure difference curve at both ends of the hydro-pneumatic spring damping hole at different temperatures basically coincides with the curve at room temperature. Each temperature range corresponds to a suitable damping hole diameter, so that the oil and gas spring has the best damping characteristics. The corresponding relationship between temperature and damping hole diameter was obtained through simulation as follows:

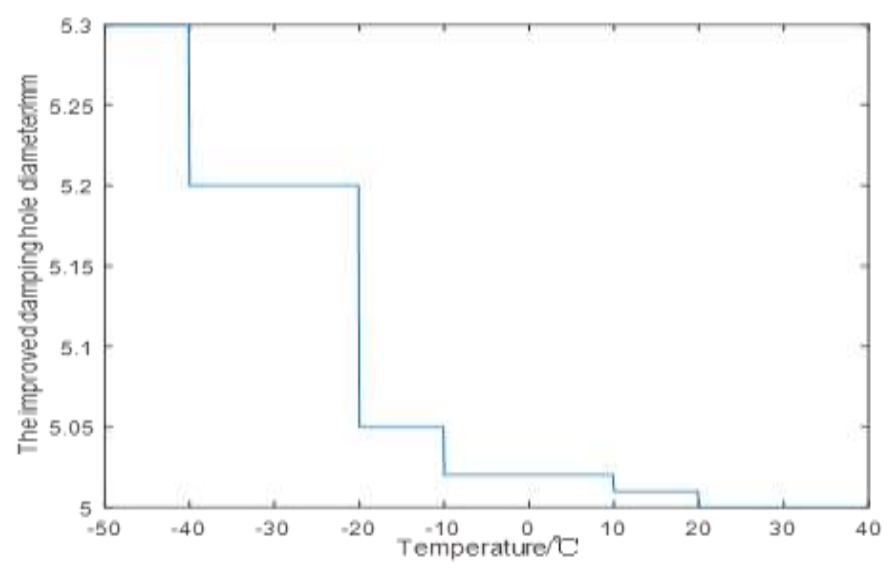

Fig.8: The relationship of improved damping hole diameter and temperature

\section{CONCLUSION}

When the vehicle is driven at low temperature, its absolute viscosity will increase, resulting in excessive damping force, which will increase the difficulty of strength design of hydro-pneumatic springs. If the diameter of damping hole is appropriately increased, the damping force of hydropneumatic spring will be maintained at the optimal damping. By adding a solenoid proportional reversing valve to the hydro-pneumatic spring, the valve can be connected to the appropriate diameter of the damping hole at different temperatures to ensure the normal ride of the vehicle.

\section{REFEIENCES}

1. Renzhi Wu. Dynamic Modeling Simulation and Experimental Study of Hydro-Pneumatic Suspension System [D]. Zhejiang: Zhejiang University, 2000:27-35.

2. Wangyu Wang. Automobile Design (Fourth Edition) [M]. Beijing: China Machine Press, 2004: 209-212 (In Chinese). 
3. Hongxin Zhang. Automobile Design (Second Edition) [M]. Beijing: China Machine Press, 1995174-176 (In Chinese).

4. Konghui Guo, Yuhang Chen, Yehai Yang et al. "Modeling and Simulation of a HydroPneumatic Spring Based on Internal Characteristics," 2011 Second International Conference on Mechanic Automation and Control Engineering, Hohhot, 2011, pp. 5910-5915.

5. Quan Liang, Jichen Xie, Liwei Nei.Advanced tutorial on AMESim computer simulation of hydraulic systems [M]. Beijing: China Machine Press, 2014.

6. Changcheng Zhou, Renxi Hu,Wei Xu.Sdudy on the Influence of Oil Temperature to Throttle Valve Parameters of Hydro-pneumatic Spring[J]. Machine Tool \& Hydraulics, 2008(01):8083.

7. Ying Fang,Bo li. Effect Analysis of Parameters Change on Performance of Independent Hydro Pneumatic Suspension based on AMESim[J]. Machine Tool \& Hydraulics, 2017, 45(04):133138.

8. Fugang Yan. Modeling and Analysis of the Damping Holes' Pressure Characteristic in Single Cylinders Hydro-Pneumatic Suspension [J]. Machinery Design and Manufacture, 2016(10) :232-235+239.

\section{Corresponding author: Yaqian Zhou;}

School of Transportation and Vehicle Engineering, Shandong University of Technology. 